\title{
Performance Comparison between Steam Injected Gas Turbine and Combined Cycle during Frequency Drops
}

\author{
Saeed Bahrami ${ }^{1}$, Ali Ghaffari ${ }^{1}$, Magnus Genrup ${ }^{2}$ and Marcus Thern ${ }^{2, *}$ \\ 1 Department of Mechanical Engineering, K.N. Toosi University of Technology, Pardis Street, \\ Vanak Square, Tehran 19991 43344, Iran; E-Mails: saeed.bahrami@gmail.com (S.B.); \\ ghaffari@kntu.ac.ir (A.G.) \\ 2 Division of Thermal Power Engineering, Department of Energy Sciences, Lund University, \\ Ole Römers väg 1, Lund SE-221 00, Sweden; E-Mail: magnus.genrup@energy.lth.se \\ * Author to whom correspondence should be addressed; E-Mail: marcus.thern@energy.lth.se; \\ Tel.: +46-46-222-4112; Fax: +46-46-222-4717.
}

Academic Editor: Chang Sik Lee

Received: 5 May 2015 / Accepted: 17 July 2015 / Published: 24 July 2015

\begin{abstract}
Single-shaft gas turbine and its cycles are sensitive to frequency drops and, therefore, sudden change loads or large frequency dips might affect their stability. This phenomenon is related to the reduction of the air mass flow passing through the machine during the frequency dips, which might lead to an interaction between governor and temperature control loop. In this paper, the performance of the combined cycle and steam-injected gas turbine are studied during frequency dips and transient maneuvers. For this purpose, two similar units are developed based on these cycles and their performances are studied in different scenarios. The simulation results show that the steam injected gas turbine has a better performance during frequency drops and it can handle relatively larger change loads.
\end{abstract}

Keywords: combined cycle; wet cycle; STIG turbine; frequency control

\section{Introduction}

The behavior of the gas turbine and its related cycles during frequency drops differs from other popular prime movers, such as steam turbines and hydroelectric units. The difference is due to the fact that the gas turbine output power depends on its rotational speed and it decreases by reduction in the grid 
frequency. This reduction in the gas turbine output power will lead to larger frequency drops and, consequently, will affect the grid stability [1]. This issue is more important when the gas turbine is running in island mode or in smart grids with a large capacity of renewable energy, as, in these grids, there is no control over the amount of generated power by solar or wind power units and the grid frequency control would rely on fossil fuels units [2]. For this reason, the sensitivity of the gas turbine to frequency drops will make it more difficult to control the frequency in these grids. Thus, studying the behavior of the gas turbine and the cycles based on it during frequency drops will be beneficial for research in this field. Although the performance of the gas turbine during frequency drops has been studied in some research [3,4], less attention has been devoted to the behavior of the other cycles based on the gas turbine and more research is required in this field.

Single-shaft gas turbines are more popular in the power generation industry due to their simplicity, lower price, and better energy recovery from the exhaust. In single-shaft gas turbines, compressor, turbine and generator are located on the same shaft. Therefore, by reduction in grid frequency, the rotational speed of the turbine and the compressor will also decrease. This reduction in the compressor speed will reduce the air flow through the gas turbine. Consequently, the amount of injectable fuel into the combustion chamber will be limited to protect the turbine components from overheating. However, for a successful frequency recovery, more overfueling is needed and restrictions on the amount of injectable fuel into the combustion chamber will cause a further decline in the frequency. Consequently, the gas turbine would be unable to recover the frequency. This issue is more crucial near full load conditions because of the high temperature of the turbine components, or in sudden load changes where more overfueling is needed to recover the frequency $[5,6]$.

Simple cycle gas turbine is based on Brayton cycle, which has a low efficiency. Several modifications have been suggested to improve the performance and efficiency of the gas turbine for power generation applications. Combined cycle and wet cycles, such as steam-injected gas turbine (STIG), are known as the most important of these cycles, which are commercially available. The basic idea of these cycles is to recover the wasted energy from the machine exhaust gases. In the combined cycle, the exhaust energy is transferred to steam in heat recovery steam generator (HRSG) and, then, the steam energy will be converted to the electrical energy in the steam turbine. However, in the STIG cycle, the produced steam in the HRSG is injected into the combustion chamber of the gas turbine to increase the cycle efficiency and output power (Figure 1). Various features of the combined cycle and STIG cycle have been studied and compared in different studies [7-9]. For example, combined cycle has a higher efficiency in comparison to the STIG cycle, but, on the other hand, the STIG cycle is simpler and requires less capital investment. The performance of these cycles during frequency drops has not studied in details and requires more research. This study will be beneficial for power generation operators to purchase and install appropriate units to meet the requirements of their grid and expected frequency excursions.

This paper shows how the combined cycle and the STIG cycle perform during frequency dips. For this purpose, two cycles are both based on the same gas turbine, which means that they both have an equal level of technology (Table 1) that has been developed, and their performances are compared to each other in different scenarios. Moreover, the cycle's structural and operational parameters, which affect their performance during frequency drops, are highlighted. All of the simulation has been done when the units are running in island mode, which is known as the most difficult case in grid frequency control. 


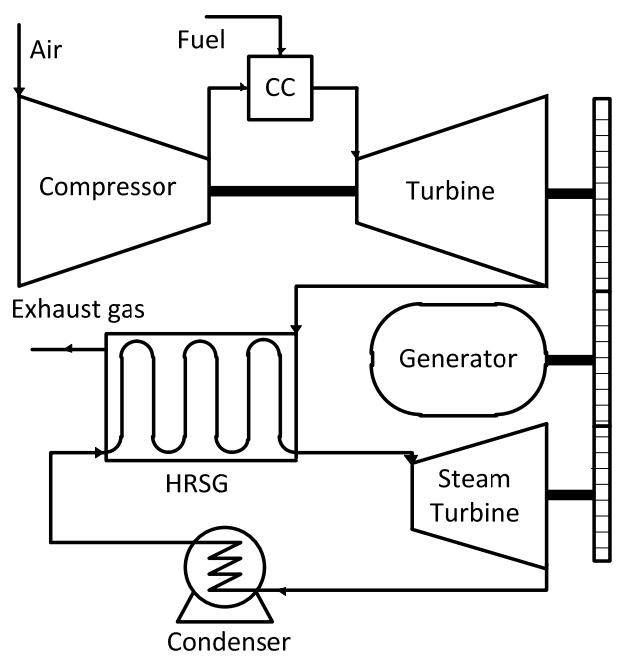

(a)

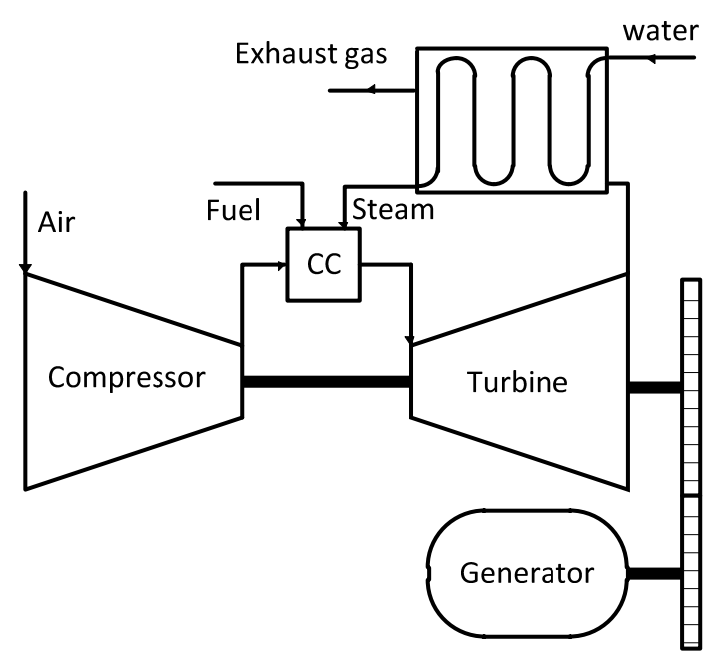

(b)

Figure 1. Combined cycle (a) and STIG cycle (b).

Table 1. The sample unit design parameters.

\begin{tabular}{|c|c|c|c|}
\hline \multicolumn{2}{|l|}{ Design Parameters } & Combined Cycle & STIC Cycle \\
\hline \multicolumn{2}{|c|}{ Compressor air mass flow $(\mathrm{Kg} / \mathrm{s})$} & 138 & 116.9 \\
\hline \multicolumn{2}{|l|}{ Pressure ratio } & 12.2 & 12.2 \\
\hline \multicolumn{2}{|c|}{ Compressor outlet temperature $\left({ }^{\circ} \mathrm{C}\right)$} & 348 & 347 \\
\hline \multicolumn{2}{|c|}{ Compressor efficiency $(\%)$} & 88.5 & 88.5 \\
\hline \multicolumn{2}{|c|}{ Fuel mass flow (Kg/s) } & 2.62 & 2.93 \\
\hline \multicolumn{2}{|c|}{ Turbine Inlet temperature $\left({ }^{\circ} \mathrm{C}\right)$} & 1097 & 1097 \\
\hline \multicolumn{2}{|c|}{ Turbine efficiency $(\%)$} & 88 & 88 \\
\hline \multicolumn{2}{|c|}{ Exhaust Temperature $\left({ }^{\circ} \mathrm{C}\right)$} & 548 & 563 \\
\hline \multicolumn{2}{|c|}{ Exhaust mass flow $(\mathrm{Kg} / \mathrm{s})$} & 140.68 & 144.2 \\
\hline \multicolumn{2}{|c|}{ Gas turbine output power (MW) } & 42.18 & 64.3 \\
\hline \multicolumn{2}{|c|}{ Steam mass flow $(\mathrm{Kg} / \mathrm{s})$} & 18.7 & 24.4 \\
\hline \multicolumn{2}{|l|}{ Drum pressure (bar) } & 45.38 & 14 \\
\hline \multirow{4}{*}{ HRSG temperature (Gas side) $\left({ }^{\circ} \mathrm{C}\right)$} & Superheater inlet & 547 & 563 \\
\hline & Evaporator inlet & 466 & 464 \\
\hline & Economizer inlet & 264 & 202 \\
\hline & Economizer outlet & 159 & 124 \\
\hline \multirow{4}{*}{ HRSG temperature (Steam side) $\left({ }^{\circ} \mathrm{C}\right)$} & Superheater outlet & 525 & 541 \\
\hline & Superheater inlet & 257 & 195 \\
\hline & Evaporator inlet & 254 & 192 \\
\hline & Economizer inlet & 60 & 60 \\
\hline \multicolumn{2}{|c|}{ Steam turbine output power (MW) } & 22.1 & - \\
\hline \multicolumn{2}{|c|}{ Net output power (MW) } & 64.3 & 64.3 \\
\hline \multicolumn{2}{|l|}{ Efficiency $(\%)$} & 49 & 43.9 \\
\hline \multicolumn{2}{|c|}{ Gas turbine inertia $\left(\mathrm{Kg} \cdot \mathrm{m}^{2}\right)$} & 1354 & 1354 \\
\hline \multicolumn{2}{|c|}{ Generator efficiency $\left(\mathrm{Kg} \cdot \mathrm{m}^{2}\right)$} & 2437 & 2437 \\
\hline \multicolumn{2}{|c|}{ Steam turbine efficiency $\left(\mathrm{Kg} \cdot \mathrm{m}^{2}\right)$} & 753 & - \\
\hline
\end{tabular}




\section{Gas Turbine Control System}

\subsection{Gas Turbine Controller}

The gas turbines are usually equipped with relatively complicated control logic, which includes several different loops, such as governor, temperature controller, acceleration controller, etc. [10]. The behavior of the gas turbine during a frequency drop is related to governor and temperature control loop and, therefore, only these two control loops will be reviewed in this section. The governor is usually known as the main control loop in the gas turbine control algorithm during its normal operation. The governor adjusts the injected fuel flow into the combustion chamber in such a way that the gas turbine output power and speed will be equal to the operator or grid demand. On the other hand, for better heat recovery from exhaust energy, exhaust gas temperature should be kept as high as possible. Therefore, the temperature control algorithm closes the compressor inlet guide vanes (IGV) during the part load operation to keep the exhaust temperature as high as possible by reducing the air flow through the gas turbine. Additionally, to increase the service life of turbine components, the temperature of gas turbine components should be kept in the design range in all operating conditions. For this purpose, the temperature control algorithm will limit the injected fuel into the combustion chamber to protect the engine from overheating. This control loop is usually inactive during the normal functions of the gas turbine and will be activated only during sudden load changes because of large overfueling or when the gas turbine is working near its full load condition because of the high temperature of the turbine components. The schematic diagram of these control loops is shown in Figure 2.

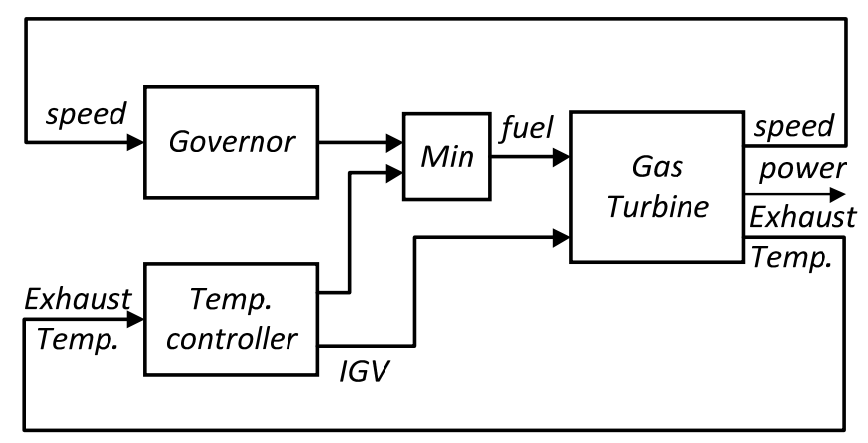

Figure 2. Simplified gas turbine control loop.

This control structure has a good performance in the normal operation of the gas turbine and it may only affect unit stability in sudden change loads. This phenomenon can be explained as follows. When the turbine load increases, its speed will be decreased proportional to the increase in turbine load. By reduction in turbine speed, the compressor air mass flow rate will be reduced and, thus, the temperature of combustion gases will increase. On the other hand, the governor will increase the fuel flow into the combustion chamber to produce more power and recover the frequency. Therefore, the temperature in the combustion chamber will be increased further. Consequently, the temperature control algorithm would try to control the temperature by opening the compressor IGVs and increasing the air mass flow rate through the gas turbine. However, in the case of large or sudden change loads, this method will not work due to the slow dynamic of IGVs actuators and air inertia. As a result, the temperature control algorithm will limit the fuel flow into the combustion chamber to protect the 
machine components from overheating. By limiting the amount of fuel, the required power to balance the new demand and recovering the frequency cannot be supplied and the speed will continue to decrease. Therefore, frequency recovery will not be possible and the turbine will be unstable. In addition, when the turbine is running near its full load, due to the higher operating temperature of turbine components, and since the IGVs are fully open, the temperature control algorithm will be activated faster and frequency control will be much more difficult. More details about this control logic can be found in related references $[3,11]$.

\subsection{Wet Cycle and Combined Cycle Differences in Frequency Control}

Wet cycle and combined cycle will show different behavior during frequency drops due to the differences in their structural and operational parameters. These important parameters can be summarized as follows.

\subsubsection{Available Power in Transient Maneuvers}

In combined cycle power plants, the gas turbine produces about two-thirds of the output power and the remaining is provided by the steam turbine. In most of the modern combined cycle power plants, the HRSG and steam turbine are controlled according to the sliding pressure control logic for better thermal efficiency. In this control logic, the steam turbine inlet valve is fully open in most of the operating conditions. Therefore, the stored steam in the HRSG's drum will be negligible and, consequently, there will be an inherent delay between the increase in the fuel flow to the combustion chamber of the gas turbine and a notable change in the power output of the steam turbine. Consequently, the transient performance of modern combined-cycle power plants during frequency drops depends entirely on the gas turbine performance [5]. In other words, only two-thirds of the unit capacity, which is related to the gas turbine, can be exploited during transient maneuvers. As a result, in all of the simulations of the current work, the output power of steam turbine during transient maneuvers is considered to be constant and equal to its output power before the frequency drop. On the other hand, in the STIG cycle, the steam is usually injected with constant pressure. Thus, the delay between the changes in the fuel follow into the gas turbine combustion chamber and changes in the flow and temperature of the injected steam will be present in this cycle as well. Therefore, in transient maneuvers during the frequency drops, the temperature and flow of the injected steam is constant, but all of the capacity of the unit can be used for frequency recovery. In simulations of the current study, the flow and temperature of the injected steam during transient maneuvers is kept constant and equal to its value before the frequency drop. In summary, about two-thirds of the combined cycle unit capacity, and almost all of the capacity of the wet cycle, can be used in transient maneuvers. For this reason, from available power in transient maneuvers point of view, the wet cycle has more advantages over the combined cycle.

\subsubsection{Gas Turbine Working Temperature}

The highest temperature in the gas turbine components is related to turbine inlet temperature (TIT). Therefore, the temperature control algorithm usually controls this temperature to protect the turbine from overheating. Figure 3 shows the steady state turbine inlet temperature for two similar units based on the 
STIG cycle and the combined cycle. As the figure indicates, at a certain load, the STIG cycle turbine inlet temperature is higher than the combined cycle. The difference is larger at lower loads and it becomes zero at a full load. The higher turbine inlet temperature for wet cycle will cause the temperature control loop to be activated faster, which limits the power output of the gas turbine. Thus, the gas turbine may become unstable faster during sudden load changes or grid frequency dips.

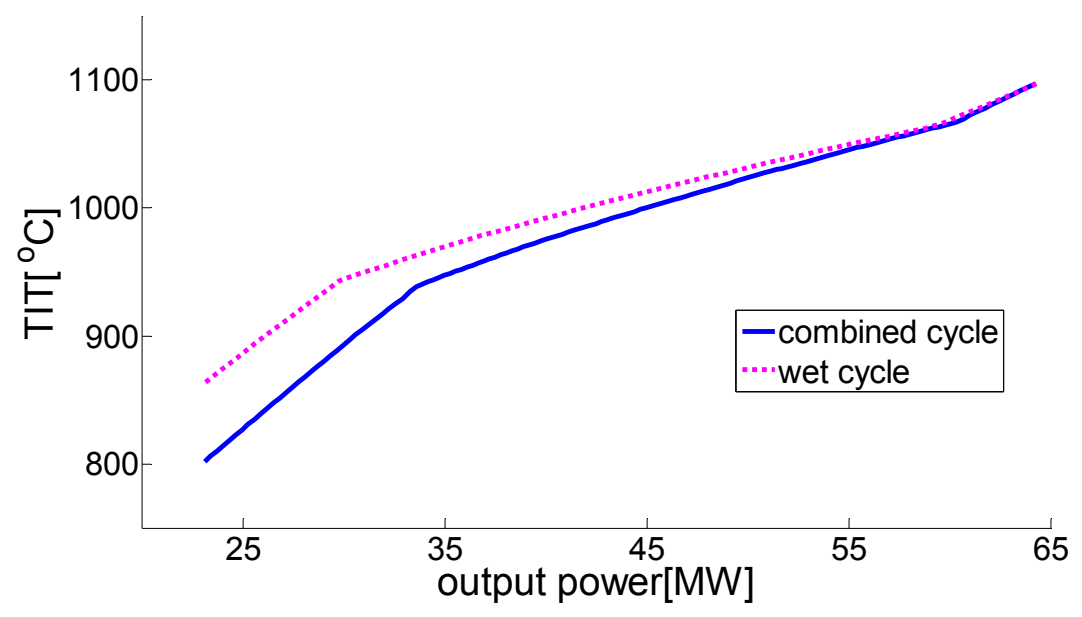

Figure 3. Combined-cycle $v s$. STIG cycle turbine inlet temperature (TIT) in a steady state condition.

\subsubsection{Working Fluid}

Steam has a higher specific heat capacity in comparison to air and other combustion products. As a result, the working fluid in the wet cycle, which contains more water vapor, has a higher heat capacity. It is important because if the turbine working fluid has a higher heat capacity, for a certain amount of fuel that enters to the combustion chamber, the working fluid will have less of a temperature increase. Therefore, during the frequency drops in which the governor injects more fuel into the combustion chamber, whichever the specific heat capacity of the working fluid is higher, the probability that the turbine temperature control loop is activated and prevents the turbine from being loaded will be lower. For this reason, from the point of view of the working fluid properties, the wet cycle has a better condition in comparison to the combined cycle.

\subsubsection{Rotating Inertia}

In combined cycle power plants, usually, a single generator is used for the gas turbine and the steam turbine. As a result, in the combined cycle, the inertia of the unit includes generators, gas turbine, and steam turbine inertia. While in the wet cycle the unit inertia is composed of the gas turbine and generator only. Therefore, for two similar units, based on the STIG cycle and the combined cycle, the combined cycle has a greater inertia. In other words, for an identical load change in two similar units, based on the wet cycle and combined cycle, the wet cycle will experience a greater frequency drop.

\section{Simulation Results and Discussion}

To compare the performance of the combined cycle and the STIG cycle during frequency dips, two similar units with the same output power are considered in this work. These two units are developed 
based on the available data from the GE6b gas turbine and their rated output power is $64 \mathrm{MW}$ at ISO conditions. Due to the available technology level for compressor design and the materials used in turbine blades, the compressor pressure ratio and turbine inlet temperature are considered equal for both of the cycles. Other design variables for these cycles at full load condition are listed in Table 1. To simulate these cycles, a mathematical model is developed based on physical laws, such as conservation of mass and energy and the characteristics of unit components, such as turbine and compressor maps. The details of this modeling approach for gas turbine [6,10], HRSG, and steam turbine [8] can be found in related references. The physical model along with the necessary control loops are implemented in the MATLAB ${ }^{\circledR} /$ Simulink environment.

To evaluate and compare the performance of the STIG cycle and the combined cycle, two different scenarios have been considered. In the first scenario, step change load has been applied to both units when they are running in island mode. In these simulations, the speed deviation, which is important from grid point of view, and turbine inlet temperature, which affect the gas turbine component service life, are compared together. The simulation results for different change loads are shown in Figures 4-6. The most important results of this simulation can be summarized as follows. For small load changes, combined cycle has a slightly smaller frequency drop in comparison to the STIG cycle. This is because, for small change loads, the inertia of the unit is the most important parameter and the combined cycle has a higher inertia in comparison to the STIG cycle. However, for medium and large change loads, wet cycle frequency drop is smaller than the combined cycle. This is due to the fact that in medium and large loads, the size of frequency drop depends more on the unit response speed than the unit inertia, and since the STIG cycle has more available power during transient maneuvers, its response will be faster in comparison to the combined cycle. On the other hand, although the STIG cycle turbine inlet temperature is higher than the combined cycle in steady state operating condition, except for a certain increase in the injected fuel, the combined cycle turbine inlet temperature increase will be bigger than the STIG cycle's. Consequently, in a large change load where a large amount of overfueling is required for frequency recovery, the turbine inlet temperature deviation from its steady state operating point will be bigger for the combined cycle. This would result in a faster activation of the temperature control loop for the combined cycle and, as a result, the amount of injectable fuel into the gas turbine combustion chamber will be limited. The limitation in the amount of overfueling makes the unit unstable because the unit cannot provide the load required by the controller. This, in turn, leads to a frequency drop as the unit fails to provide the given load requirement (Figure 6). The main reason for this phenomenon can be discussed as follows. First of all, the wet cycle working fluid has a higher specific heat capacity. Thus, for certain increases in fuel flow, the combined cycle working fluid will experience a higher temperature rise. Moreover, since only about two-thirds of the combined cycle capacity is available in transient maneuvers, the gas turbine in the combined cycle unit has to produce more power than its steady-state performance to compensate for the required remaining power. Therefore, for the combined cycle, the turbine inlet temperature will be higher than its steady state operating condition. 


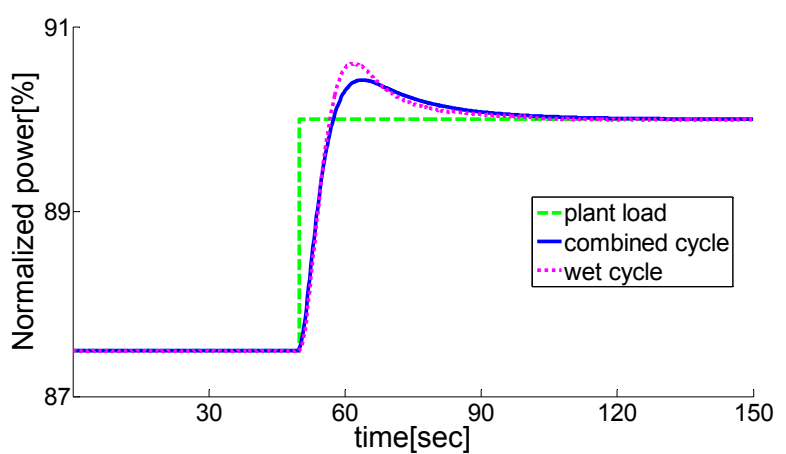

(a)

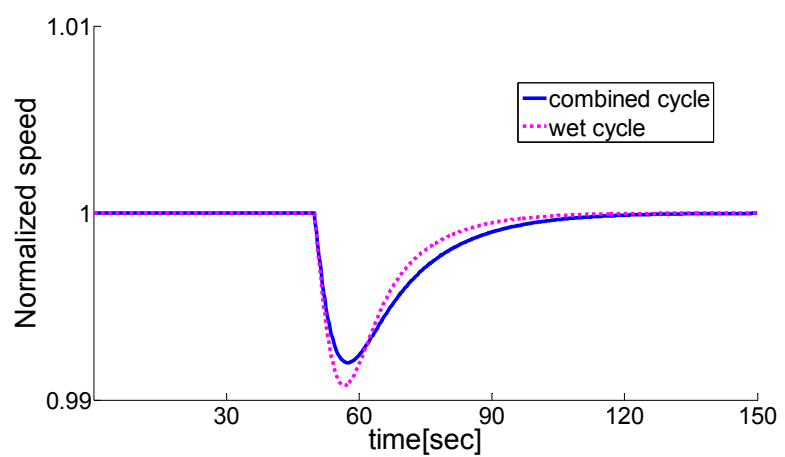

(b)

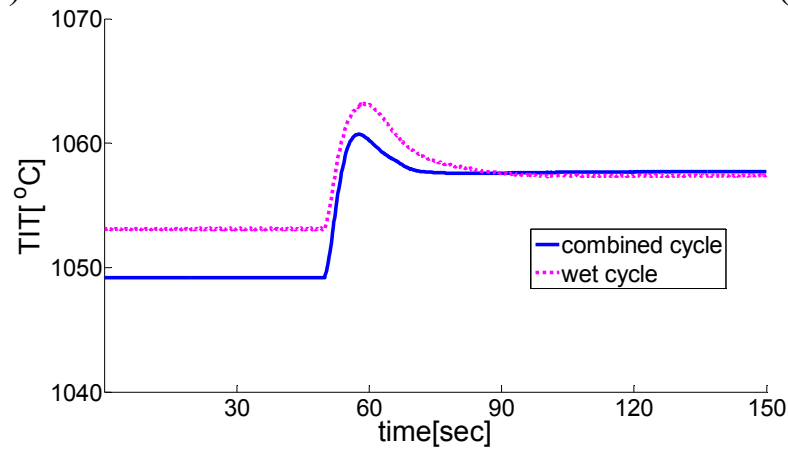

(c)

Figure 4. Performance of the combined cycle $v s$. STIG cycle-2.5\% step change load (plant loading from $87.5 \%$ to $90 \%$ of plant load); (a) Normalized power, (b) Normalized speed, (c) Turbine inlet temperature (TIT).

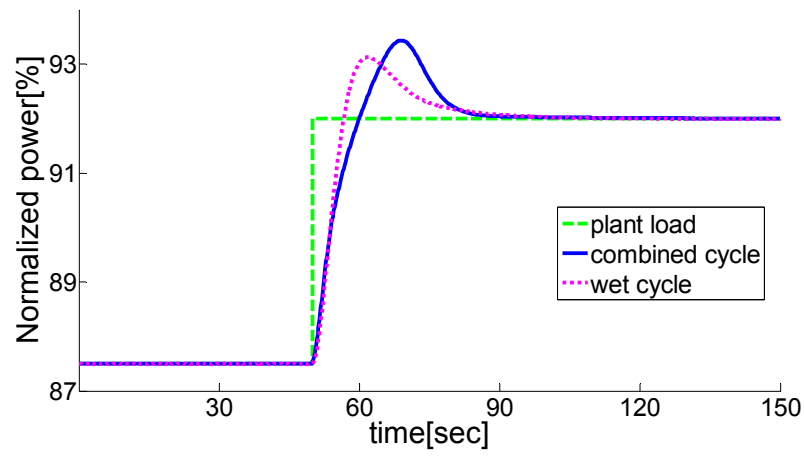

(a)

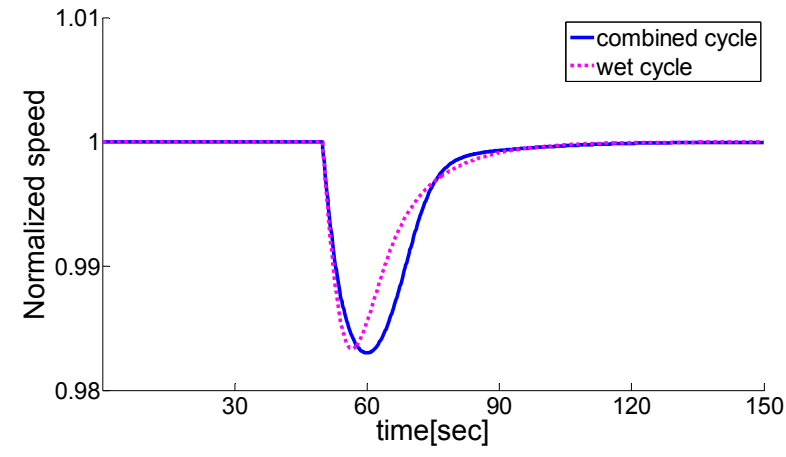

(b)

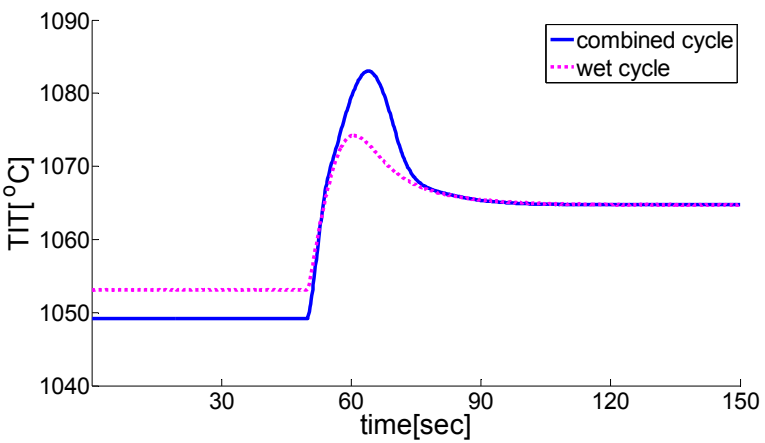

(c)

Figure 5. Performance of the combined cycle $v s$. STIG cycle- $4.5 \%$ step change load (plant loading from $87.5 \%$ to $92 \%$ of plant load); (a) Normalized power, (b) Normalized speed, (c) Turbine inlet temperature (TIT). 


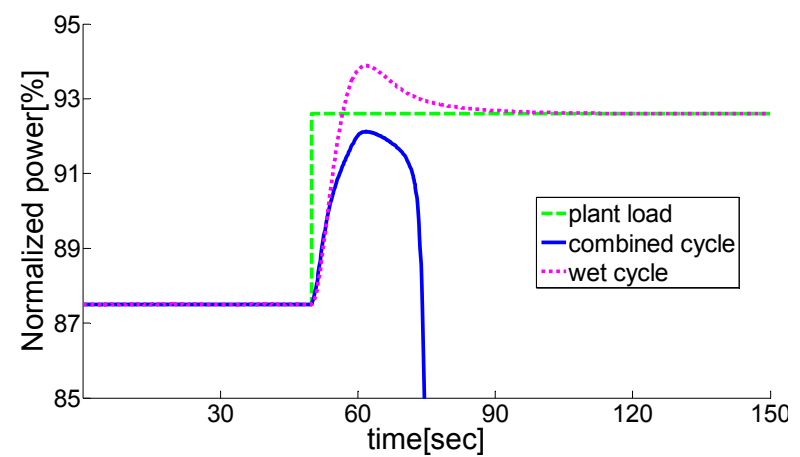

(a)

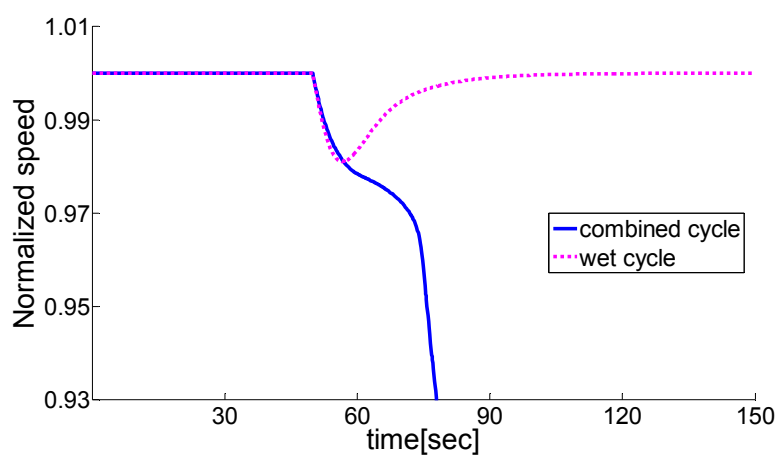

(b)

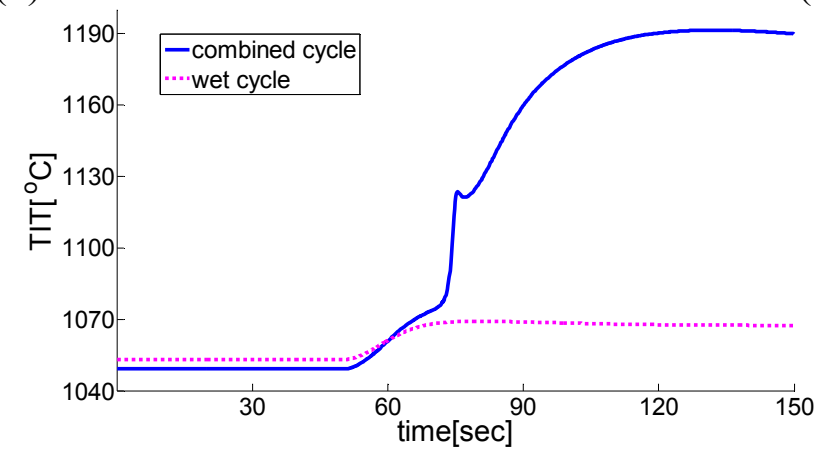

(c)

Figure 6. Performance of the combined cycle $v s$. STIG cycle- $5.1 \%$ step change load (plant loading from $87.5 \%$ to $92.6 \%$ of plant load) — combined-cycle instability limit; (a) Normalized power, (b) Normalized speed, (c) Turbine inlet temperature (TIT).

In the second scenario, the maximum tolerable step change load is calculated for the STIG cycle and the combined cycle when they are running in island mode. The results of these calculations at different loads are summarized in Figure 7. As is shown in this figure, the STIG cycle outperforms the combined cycle in the sudden change loads. This superior performance of the STIG unit is almost twice as good as the similar combined cycle unit in some of the operating conditions, which is very interesting. The main reason for this phenomenon is related to the fact that the wet cycle can use all of its capacity during transient maneuvers and its working fluid has a higher specific heat capacity. It should be noted that the difference between the performance of the combined-cycle and the wet cycle is smaller near full load condition. This is because, at near full load conditions, the unit can experience only small load changes and, therefore, the combined-cycle inertia can compensate for the higher capacity of the wet cycle during transient maneuvers.

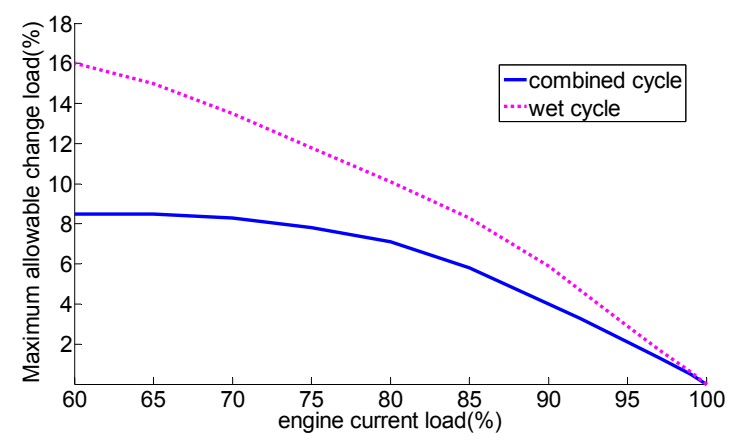

Figure 7. Maximum allowable change load for STIG cycle vs. combined-cycle. 
As the simulation results shows, for small change loads the combined cycle has a better performance in comparison to the wet cycle, and for large change loads the wet cycle would have superior performance in frequency drops. This issue will be beneficial from the point of view that one can design flexible gas turbine units, which can work either on the combined cycle or the wet cycle. Then, the operators can chose between them, according the requirements of their grids and expected frequency excursions. For example, during night, when large change loads are not expected, the unit can work on the combined cycle for a higher efficiency and better performance while, near sunset where a larger change load is expected, the unit can work on the wet cycle for better frequency recovery.

\section{Conclusions}

Sudden change loads and large frequency drops may affect the stability of a gas turbine and the cycles based on it. Consequently, the performance of these cycles during frequency dips should be taken into account before selecting the appropriate unit. In this paper, the performance of two important cycles, based on gas turbines - the combined cycle and the steam-injected gas turbine (STIG cycle) — are investigated during transient maneuvers and frequency drops. For this purpose, two similar units are considered based on these cycles, and their performances are investigated in different scenarios. The main results from these investigations can be summarized as follows:

- In small load changes, the frequency drop for the combined cycle will be smaller in comparison to the STIG cycle. However, for medium and large load changes the combined cycle frequency drop will be larger.

- The STIG cycle has a better performance in handling large frequency drops in comparison to the combined cycle. The most important reason for better performance of the STIG cycle is related to the amount of available power in transient maneuvers and higher specific heat capacity of working fluid in this cycle.

- $\quad$ The STIG cycle turbine inlet temperature is higher than the combined cycle in the same load. However, for the same change in units load, change in combined cycle turbine inlet temperature will be higher.

- Designing flexible unit, which can work either on the STIG cycle or the combined cycle, would be beneficial to have better efficiency and performance during frequency drops.

\section{Acknowledgments}

The authors also take this opportunity to express a deep sense of gratitude to Abbas Aliabadi and MAPNA Group for their support and valuable information which helped us in completing this task through various stages.

\section{Author Contributions}

This paper was a part of Saeed Bahrami PhD thesis under supervision of Ali Ghaffari. Marcus Thern and Magnus Genrup provided the required supervision for modeling the cycles. Saeed Bahrami and Marcus Thern have prepared this manuscript. 


\section{Conflicts of Interest}

The authors declare no conflict of interest.

\section{References}

1. Mello, F.P.; Ahner, D.J. Dynamic models for combined cycle plants in power system studies. IEEE Trans. Power Syst. 1994, 9, 1698-1708.

2. Camacho, E.F.; Samad, T.; Garcia-Sanz, M.; Hiskens, I. Control for Renewable Energy and Smart Grids. In The Impact of Control Technology; Samad, T., Annaswamy, A.M., Eds.; IEEE Control Systems Society: New York, NY, USA, 2011; pp. 69-88.

3. Kakimoto, N.; Baba, K. Performance of gas turbine-based plants during frequency drops. IEEE Trans. Power Syst. 2003, 18, 1110-1115.

4. Lalor, G.; O’Malley, M.J. Frequency Control on an Island Power System with Increasing Proportions of Combined Cycle Gas Turbines. In Proceedings of the IEEE Power Tech Conference, Bologna, Italy, 23-26 June 2003.

5. Lalor, G.; Ritchie, J.; Flynn, D.; O’Malley, M.J. The impact of combined-cycle gas turbine short term dynamics on frequency control. IEEE Trans. Power Syst. 2005, 20, 1456-1464.

6. Walsh, P.P.; Fletcher, P. Gas Turbine Performance, 2nd ed.; Blackwell Science Ltd.: Oxford, UK, 2006.

7. Rice, I.G. Steam-Injected Gas Turbine Analysis-Part I-Steam Rates. In Proceedings of the International Gas Turbine and Aeroengine Congress and Exposition, Cincinnati, OH, USA, 24-27 May 1993.

8. Kehlhofer, R.; Rukes, B.; Hannemann, F.; Stirnimann, F. Combined-Cycle Gas \& Steam Turbine Power Plants; PennWell Corporation: Tulsa, OK, USA, 2009.

9. Jonsson, M.; Yan, J. Humidified gas turbines-A review of proposed and implemented cycles. Energy 2005, 30, 1013-1078.

10. Rowen, W.I. Simplified mathematical representations of heavy-duty gas turbines. J. Eng. Gas Turbines Power 1983, 105, 865-869.

11. Bahrami, S.; Ghaffari, A.; Thern, M. Improving the transient performance of the gas turbine by steam injection during frequency dips. Energies 2013, 6, 5283-5296.

(C) 2015 by the authors; licensee MDPI, Basel, Switzerland. This article is an open access article distributed under the terms and conditions of the Creative Commons Attribution license (http://creativecommons.org/licenses/by/4.0/). 